\title{
Sleep Deprivation and workplace deviance: a mediation approach
}

\author{
Usmani, Sania $^{1}$, Kumari Kalpina ${ }^{2}$, Husain, Javed ${ }^{3}$ \\ ${ }^{1}$ (Business Administration, Iqra University, Pakistan) \\ ${ }^{2}$ (Business Administration, Iqra University, Pakistan) \\ ${ }^{3}$ (Business Administration, Iqra University, Pakistan)
}

\begin{abstract}
This research paper examines the effect of sleep deprivation on workplace deviance through selfregulatory mechanism. The self- regulatory mechanism includes state hostility and self-control. Sleep deprivation decreases individual's self-control while increasing state hostility leads to increased workplace deviance. The sample has been taken from medical residents from 6 hospitals in Karachi, Pakistan. Findings suggest that self-control does not mediate the relation between sleep deprivation and workplace deviance but state hostility fully mediates the relationship between sleep deprivation and workplace deviance.
\end{abstract}

Keywords: Workplace Deviance, Sleep deprivation, Structural Equation Modeling, Mediation

\section{INTRODUCTION}

An unethical and deviant behavior is an emerging problem in the organizations these days. Research has shown that deviant behaviours pose social and economic threats to organizations [1]. According to Harper, [2] 33 to 75 percent of all employees engage in violent behaviors such as deceit, defacement, theft, and damage. Some common, yet harmful violent behaviors involve lying [3], withholding efforts [4] spreading rumors [5], and absenteeism [6]. Such attitudes violate workplace ethics and therefore organizational researchers have focused on various types of negative behaviors in the offices [5], [7], [8]. Employee theft, deceit and sabotage, rude behavior, playing mean tricks and arguments are assumed to be the fastest growing deviant workplace behaviors. Considering the increasing prevalence of such behaviors and the vast economic and social expenses related with such behaviors has urged the researchers to focus on this topic [9], [10], [11], [12].

Workplace deviance is known as "voluntary behaviour that violates significant organizational norms, and in so doing, threatens the well-being of the organization and/or its members" [13: 556]. Workplace deviance can also be described as deliberately causing damage to the business [14].Deviant behaviours of one employee negatively affect's other employees as well. Employees who work with and around the deviant employees experience stress related issues, anxiety, lack of confidence, impaired self-esteem, insecurity at work, and high turnover [15].

Self-regulatory resource theories[16] or "the internal resources available to inhibit, override, or alter responses that may arise as a result of physiological processes, habit, learning, or the press of the situation" (17: 86), help separate sleep deprivation as an originator to deviant behaviour. Workplace deviance arises because of impairments in self-regulatory abilities related to behaviour and emotions.

As the number of working hours or late sittings have been increasing, the culture of sleep deprivation is also increasing therefore sleep research is now becoming pertinent to organizations. Sleep deprivation has effects on concentration, performance on challenging tasks, decision-making capacity, work-related injuries and welfare of workers [18]; [19]; [20]. This study offers a significant contribution to the organizational literature by exploring social, psychological, sleep and neuro cognitive researches to assess the impact of sleep deprivation on workplace deviance.

Self-regulatory resource is the result of sleep deprivation and it has two components; self-control and hostility. These two conditions underlie the association between sleep deprivation and workplace deviance. Selfcontrol is defined as the condition of energy and strength which helps to control over ones emotions and behaviour [21]; [22] while hostility is defined as an emotional negative condition which involves feelings of repulsion, petulance, and rage [23].

The self- regulatory component will help to identify the underlying structure involved in sleep deprivation on workplace deviance therefore it is said to perform a mediating role in between sleep deprivation and work place deviance.In view of the extensive scope of workplace deviance, the present study focuses on testing the association between sleep deprivation and workplace deviance mediated through self-control and hostility.

\section{Workplace Deviance}

Robinson \& Bennett [13] denoted workplace deviance behaviours as a) voluntary; b) they disrupt organizational rules, and c) threatens the welfare of the organizational members. Deviant behaviours can be classified into two i.e. whether they are organizational or interpersonal [1], [13]. Organizational deviance 
includes a) Production deviance: It involves behaviors such as taking unnecessary breaks, leaving early, deliberately work slowly, and wasting work resources and b) Property deviance: It involves behaviors such as damaging equipment, taking bribes, lying about hours worked, and theft.

Interpersonal deviance includes a) Political deviance: It involves behavior such as favoritism, chattering about colleagues, accusing fellow coworkers, and unconstructive or dysfunctional competition and b) Personal aggression: It involves sexual harassment, abusing verbally, theft from colleagues, and threatening colleagues.

Deviance is driven by specific cognitions such as thoughts of vengeance or retaliation or for personal gain [24], [25]; [26]. Deviance is also driven by the need to express emotions of anger or frustration [27].

\section{Self-Regulation}

Self-regulation is an important underlying mechanism of workplace deviance. A person's ability to regulate or control his or her emotions and behaviours will affect the degree to which he or she acts in a deviant way. When self-regulatory mechanisms fail, deviant behaviour tend to occur more profusely [28]; [29].

Self-regulatory resource models advocate that behaviours and emotions are directed by energy [30]; [21]. These resources allow people to govern emotions, impulses, and desires. Furthermore, even a steady selfregulatory capacity can be depleted due to scarce resource availability [31]. Sleep deprivation is likely to cause depletion in self-regulatory resources, which can lead to deviance in behaviour.

\subsubsection{Self-Control and State Hostility}

The concept of self-regulatory resources is extensive. Self-regulation is composed by regulating emotions and behaviour [21]. The behavioural aspect is related to self-control while the emotional aspect relates to state hostility. Self-regulatory resource depletion increases work place deviance through these two mechanisms; self-control and state hostility. Sleep deprivation is logically and practically linked to both selfcontrol and state hostility, which leads to deviant behaviour. Self-control and hostility are potential mediators between sleep deprivation and workplace deviance relationship.

\section{Self-control}

Self-control means how much control one has on his or her behaviour. Self-regulatory resources govern an individual's degree of self-control [16]; [21]. Self-control is decreased when self-regulatory resources deplete [32]; [31]. Researchers indicate that sleep deprivation also damages self-control as sleep deprivation effects the functioning of the brain [17].

Research has found that individuals who lack self-control are unable to repress or prevent impulsive behaviours therefore self-control is linked to deviant behaviour often leading to taking risky decisions [31]; [33]. Mead, Baumeister, Gino, Schweitzer, and Ariely [34] found that respondents who did a task requiring energy which lead to depletion of self-control were more inclined to cheat if given the opportunity. The effect of only self-control on workplace deviance has been substantiated [26]; [35]; [36].In conclusion sleep deprivation reduces self-control and escalates the frequency of workplace deviance.

\section{State hostility}

State hostility is related to the emotional aspect of self-regulation where individuals control the emotions when they experience them, and control the way they express them. As the prefrontal cortex also regulates emotions besides the behaviour of an individual therefore the capacity to regulate emotions is also impaired due to sleep deprivation [37]; [38].

Research indicates that injury to the prefrontal cortex leads to poor emotional regulation and increase in negative emotions [37]. Laboratory studies are uncertain whether self-regulatory resource depletion leads to negative emotions or not [21]; [32] but it is certain that depletion reduces the capacity to control negative feelings [39]; [32].

Individuals who are deprived of sleep have low regulatory resources and are likely to react with anger and hostility to difficult situations. Durmer and Dinges [40] found that negative emotions are a consequence of nearly all forms of sleep deprivation. Their research indicated that sleep deprivation impacts experience and results in irritable and hostile expressions [41]; [19]; [42]. Zohar et al. [42] found that loss of sleep increased the degree of emotional responses of medical residents' to situations which required self-regulation. In the event of sleep loss when self-regulatory resource depletion undermines emotional regulation, negative emotions are expressed [43].

Negative emotions are also related to workplace deviance [44]; [27]; [45]; [43]. Emotions like anger and hostility seem to be more problematic as they are linked to impulsive reactions [46]. From the perspective of self-regulation, when individuals experience negative feelings they react in two ways. Firstly, their short term priority is to regulate their emotions and express them as they will feel good, and in doing so they fail to attain 
self-control or the behavioural aspect of self-regulation [47]; [48]. Consequently, negative emotions tend to make individuals aggressive, and lead them to behave deviantly if they believe their mood will improve through their act.

Secondly, the energy from the similar group of resources used in the regulation of behaviour is required to regulate emotions also [47]; [48]; [50]. In case of expanding these resources to control negative feelings it becomes hard to control deviant compulsions [51].According to the self-regulatory resource theories, a conclusion can be driven that sleep deprivation tends to escalate hostility and subsequently the occurrence of workplace deviance.

\section{Sleep Deprivation}

Sleep determines an individual's attentiveness. It is a stabilizing process which has a healing effect on the mind [52]; [53]. Sleep deprivation (total or partial) induces reduced thinking or reasoning capacity [54]. A night without sleep results in total sleep deprivation while shortened or interrupted sleep leads to partial sleep deprivation. The ideal sleep depends on various factors e.g. individuals sleep requirements, diseases such as insomnia which causes sleep restriction, or sleep debt [55]; [56]. According to Ferrara \& De Gennaro [55] 7 or more hours of sleep is sufficient for most people in a day.

The effects of sleep deprivation are much more significant for divergent/creative thinking and selfregulation rather than rational thinking and cognition [19]. Substantial researches provide evidence that people with sleep deprivation perform poorly on tasks which require innovation e.g. risk analysis and strategic planning while perform satisfactorily on standardized tests [57]; [58]

Sleep deprivation may be a result of factors such as working in shifts, increased workloads, sleep disorders, life style and effect of medicines [19]; [52]. Partial or incomplete sleep deprivation is common than total sleep deprivation but some jobs require total sleep deprivation for individuals who work for continuous 24 hours at least once a week e.g., doctors and physicians, [52], military professionals, and international managers who frequently need to adjust to changes in time zone.

In neuroscientific research, sleep deprivation results from diminished brain function, mainly in the prefrontal cortex. Prefrontal cortex comprises of a set of neocortical structures which are part of a web in the brain that has a supervisory control. It also has the capacity to regulate emotions and behaviours [59]; [60]; [40];[61].

Sleep-deprived individuals frequently engage in inappropriate interpersonal behaviours, act impulsively and rudely and do not abide by to social values [19]; [62]. These researches indicate that damage to the prefrontal cortex escalates rebellious behaviours like deception, anger, and viciousness [63].

Glucose is a fuel for the brain. It gives energy to the brain which is vital for the functioning of the executive or supervisory control and self-regulation [64]. Sleep deprivation reduces the glucose metabolism level and damages the prefrontal cortex, thus, decreases this supervisory or executive control over the brain, and ultimately depletes self-regulatory resources [65]; [66]. Self- regulatory resource depletion is a phenomenon which can be understood by the impairment in the prefrontal cortex region of the brain. Sleep deprivation damages the executive function of the brain (self-regulation) which leads to inappropriate and impulsive behaviours in the workplace known as workplace deviance.

Three hypotheses have been developed in this research to check the impact of sleep deprivation on workplace deviance through self-regulation. As discussed above that self-regulation comprises of two components known as self-control (behaviour) and state hostility (emotions) therefore these two are the mediators in the model given in figure 1.Self-control and state hostility represents the two mechanisms underlying the relationship between sleep deprivation and workplace deviance. Self-control has a negative association with workplace deviance while state hostility has a positive association with workplace deviance. Following are the hypotheses developed to test the association between sleep deprivation and workplace deviance mediated by self-control and state hostility:

Hypothesis 1: Sleep deprivation increases workplace deviance behaviours.

Hypothesis 2: Self-control mediates the relationship between sleep deprivation and workplace deviance.

Hypothesis 3: State hostility mediates the relationship between sleep deprivation and workplace deviance. 
Fig 1: Conceptual Model

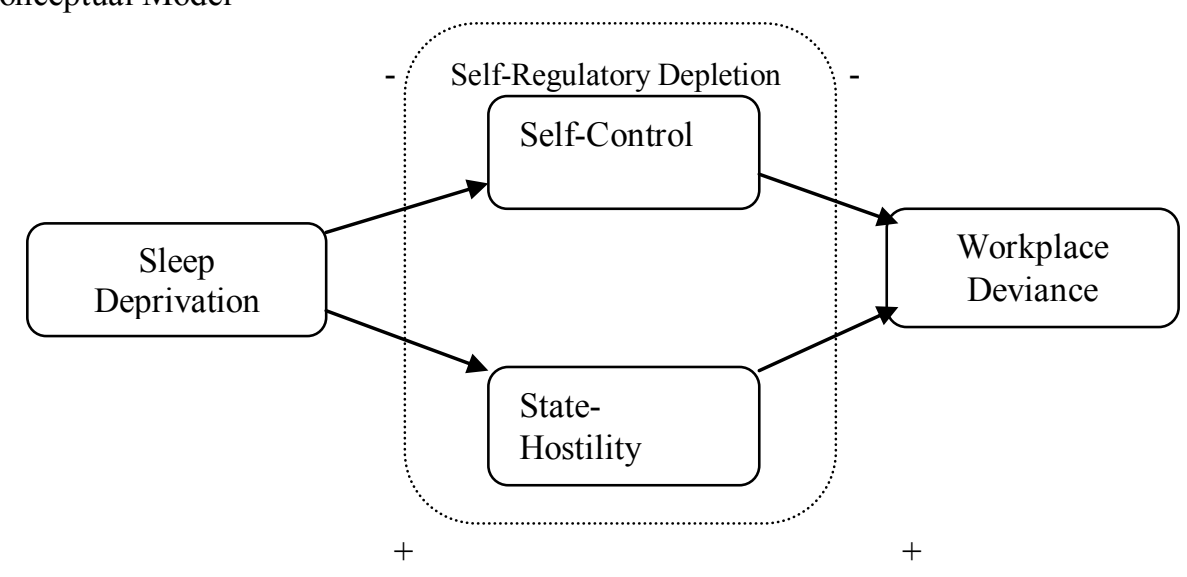

\section{Methodology}

\section{Sample Description}

This study has been conducted on 200 medical residents to test the relationship between sleep deprivation and workplace deviance. These residents were taken from few hospitals in Karachi, Pakistan. There are 150 hospitals in Karachi; public and private altogether. It was difficult to take sample from every hospital due to time constraint therefore 6 hospitals were chosen namely; Aga Khan University Hospital, Liaquat National Hospital, Jinnah Medical Hospital, Medicare Hospital, Dow University Hospital and PNS Shifa. Convenience based sampling was used. Out of 200, 81 are male and 119 are female, i.e. the ratio of male to female in this study is 40:60, approximately. All the respondents were between the ages of 26 to 30 .

\section{Procedures}

All the variables were self- reported therefore few attempts were made to deal with common method bias issue in the study by following the recommendations of Podsakoff, MacKenzie, Lee, and Podsakoff [67], Firstly, to maximize confidentiality, respondents were asked to keep themselves anonymous by not writing their names. Secondly, predictor and criteria variables were placed in the questionnaire at different places which followed spatial distance which reduces the recall-related biases. All the respondents were asked to fill the questionnaire which was given to them through a reference person in order to avoid socially desirable answers, avoid forced participation and if source of survey was disliked.

\section{Measures}

\section{Sleep Deprivation}

Sleep deprivation was operationalized as an open ended question in which participants indicated the sleep time they had the night previous to filling the survey. 6 hours was chosen as the cut-off point because sleeping less than 6 hours will damage the cognitive capacity, while sleeping 7 or more will not [55], [68]. Bonnet and Arand (1995) and Weinger and Ancoli Israel [52] found that 5 to 6 hours of sleep has a detrimental effect on mood, performance, and alertness. If an individual slept 6 hours or less, so in order to indicate that case was given 1, representing sleep deprivation. Anyone who slept seven hours or more was given0, signifying no sleep deprivation.

\section{Self-Control}

Self-control was evaluated with the self-control scale [22] containing 25 items. This scale measures the perceptions of the accessibility of self-regulatory resources. Respondents rated items scale ranging from 1, "very slightly or not at all," to 5, "very much". High scores specified greater self-control.

\section{Hostility}

State hostility was measured using the subscale of Negative Affect measuring the emotion of hostility using 6 items. Negative affect is part of PANAS- X known as Positive and Negative Affect Schedule Expanded Form [23]. Items included "angry," "hostile," "irritable," "scornful," "disgusted," and "loathing". Respondents indicated the intensity of the emotion they felt in the past hour. The scale used was from 1"very slightly or not at all," to 5, "extremely". 


\section{Workplace deviance}

Workplace deviance was measured using 17 items from Christian \& Ellis [68], one item was omitted because of the cultural context "used an illegal drug or consumed alcohol on the job". Originally 19 items were used in Bennett and Robinson's [1]. Participants were asked to specify the frequency of involving in a particular behaviour (1, "never," to5, "daily"). Questions included such as "Discussed confidential information with an unauthorized person," "Worked on a personal matter instead of work for your employer," "Intentionally worked slower than you could have worked" and "Said something hurtful to someone at work," etc.

\section{Control variables}

Trait positive and negative affect (PANAS- X; [23], gender, chronic insomnia or chronic sleep issues [69], sleep debt or the accumulated number of hours slept in past two nights [68], sleep requirement was measured as the number of hours respondent felt he/she needed to sleep in order to feel relaxed [56], hours awake or the number of hours respondents had been awake before filling the questionnaire [30] are the controlled variables in this study similar to that of Christian \& Ellis, 2011, [68]. Negative and positive affect was controlled because of their association with other variables present in the study [27]. Even though in gender male tend to exert more deviant behaviour than women but as the sample in this study $60 \%$ are women but still this variable will be controlled to identify any potential significance. Chronic insomnia and sleep debt also have an impact on deviance by self-regulatory depletion therefore these were also controlled. Finally, hours awake was controlled to regulate the effects of sleeplessness duration, which is linked with exhaustion [30].

\section{Statistical technique}

Statistical technique used in this study is Structural Equation Modeling (SEM) using Amos 18 version. SEM was applied using two step modeling; in the first step Confirmatory Factor Analysis (CFA) was run respecified and in the second step Structural model paths were then added to show the direct effects of sleep deprivation on workplace deviance through state hostility and self-control mediators. Prior to that the data was analyzed for normality, outliers and missing values in SPSS 17 version and upon detection they were corrected. Also, discriminant validity, convergent validity, composite reliability, reliability coefficients have been applied and common latent factor and Herman single factor test was applied to test for any common method variance in the study.

\section{Results}

Total sample size was of 200 respondents out of which 35 outliers were found using Mahalanobis distance test and their values were less than 0.001 . These outliers were removed and the retained data was 165 respondents. Total 91 variables were collected through the questionnaire, out of which 80 belonged to their respective factors, 6 variables were sleep requirement, sleep debt, hours awake, gender, and age. Also, 5 variables were related to the time duration of chronic insomnia which were irrelevant for the analysis therefore they were not taken into consideration.

\section{Mean, Standard Deviations and Intercorrelations:}

Table 1 represents the mean, standard deviations and intercorrelations between 11 variables in the data. The correlation between sleep deprivation, self-control and hostility, hours awake, chronic insomnia, negative affect and gender were insignificant. Gender was insignificantly correlated with all the variables except sleep requirement. All the highlighted variables were insignificantly correlated.

Table 1: Descriptive Statistics: Mean, SD, and Intercorrelations

\begin{tabular}{|l|l|l|l|l|l|l|l|l|l|l|l|l|l|l|}
\hline & Variable & Mean & SD & $\mathbf{1}$ & $\mathbf{2}$ & $\mathbf{3}$ & $\mathbf{4}$ & $\mathbf{5}$ & $\mathbf{6}$ & $\mathbf{7}$ & $\mathbf{8}$ & $\mathbf{9}$ & $\mathbf{1 0}$ & $\mathbf{1 1}$ \\
\hline & Main & & & & & & & & & & & & & \\
\hline 1 & SleepDeprivation & 5.6700 & .75428 & - & & & & & & & & & & \\
\hline 2 & Self-control & 2.8380 & .82641 & -.107 & - & & & & & & & & & \\
\hline 3 & Hostility & 2.2183 & .83029 & .130 & $-.510^{* *}$ & - & & & & & & & & \\
\hline 4 & WorkplaceDeviance & 1.9288 & .62472 & $.189^{* *}$ & $-.295^{* *}$ & $.562^{* *}$ & & & & & & & & \\
\hline & Control & & & & & & & & & & & & & \\
\hline 5 & SleepDebt & 11.5950 & 1.82968 & $.476^{* *}$ & .008 & .069 & .118 & - & & & & & & \\
\hline 6 & Hoursawake & 5.3600 & 2.72351 & -.051 & $.140^{*}$ & -.067 & -.114 & .029 & - & & & & & \\
\hline 7 & Sleeprequirement & 7.7950 & .77198 & $.168^{*}$ & -.036 & $.183^{* *}$ & $.241^{* *}$ & $.151^{*}$ & .107 & - & & & & \\
\hline 8 & ChronicInsomnia & 1.2681 & .94759 & -.119 & $.276^{* *}$ & .035 & -.072 & -.122 & .099 & .003 & - & & & \\
\hline 9 & NegativeAffect & 1.9005 & .69640 & -.088 & .037 & $.552^{* *}$ & $.314^{* *}$ & .000 & .123 & $.178^{*}$ & $.378^{* *}$ & - & & \\
\hline 10 & PositiveAffect & 2.3615 & 1.08283 & -.042 & $.651^{* *}$ & $-.416^{* *}$ & $-.277^{* *}$ & .009 & $.224^{* *}$ & - & $.272^{* *}$ & $.141^{*}$ & - & \\
\hline 11 & Gender & 1.5950 & .49212 & .004 & .042 & .031 & -.019 & -.044 & .038 & $.151^{*}$ & -.016 & .109 & -.062 & - \\
\hline
\end{tabular}

$\mathrm{N}=165,{ }^{* *} \mathrm{p}<0.01,{ }^{*} \mathrm{p}<0.05$ 


\section{Exploratory Factor Analysis:}

Exploratory Factor Analysis was conducted in SPSS 17 before it was taken further in Amos for Confirmatory Factor Analysis. The underlying assumptions for factor analysis are that KMO (Kaiser-MeyerOlkin Measure of Sampling Adequacy) value must be $>0.5$ and Bartlett test of sphericity must be rejected $(p<0.05)$. Bartlett test of sphericity tests the null hypothesis that the correlation matrix is an identity matrix means there is no correlation among variables. KMO value is 0.865 and Bartlett's test value is less than 0.00 . Varimax Algorithm of Orthogonal Rotation was used to analyze 80 variables. 6 number of factors were fixed and ultimately 44 variables were retained which explained $72.74 \%$ variance in the data. These 6 factors were named chronic insomnia, positive affect, workplace deviance, negative affect, self-control and hostility. 3 factors, self-control, hostility and workplace deviance were taken in the further analysis while the rest of the three factors were control variables which were averaged to form exogenous variables and avoid clutter in AMOS.

\section{Confirmatory Factor Analysis:}

Confirmatory factor analysis was then conducted using Amos 18. CFA was used to confirm the three latent constructs of the 16 observed variables retained from EFA. The model was run three times in order to improve the goodness of fit indices i.e. CMIN/DF, TLI, CFI, RMSEA along with Chi Square and degrees of freedom. Table 2 summarizes the two CFA model specifications, final hypothesized CFA model, hypothesized structural model, and structural model with control variables. It also represents the values of chi square $\mathrm{x} 2$, degrees of freedom $d f$, CMIN/DF, TLI, CFI and RMSEA. The measurement model is a good fit; the structural model with both mediators was an average fit but the relationship between sleep deprivation and workplace deviance was only significant due to the mediators therefore phantom models were created to find which mediator was significant. After finding that self-control had no effect direct, indirect or total on workplace deviance, it was removed from the structural model. Thus the final model improved significantly and the fit indices improved significantly. Three control variables; chronic insomnia, sleep requirement and positive affect were significant in the study but due to these control variables the model was not a good fit. But even with these control variables the relationship between sleep deprivation and workplace deviance was mediated through hostility.

Table 2: Summary of Models

\begin{tabular}{|l|l|l|l|l|l|l|}
\hline & $\mathbf{x 2}$ & $\boldsymbol{d f}$ & $\mathbf{C M I N / D F}$ & TLI & CFI & RMSEA \\
\hline Measurement MODEL 1 & 296.025 & $136-35=101$ & 2.931 & 0.872 & 0.892 & 0.10 \\
\hline Measurement MODEL 2 & 213.8 & $136-41-95$ & 2.25 & 0.917 & 0.934 & 0.08 \\
\hline Hypothesized Measurement Model & 186.166 & $128-38-82$ & 2.270 & $\mathbf{0 . 9 2 3}$ & $\mathbf{0 . 9 4 0}$ & 0.08 \\
\hline Structural Model 1 & 269.047 & $136-41=95$ & 2.832 & $\mathbf{0 . 8 7 4}$ & $\mathbf{0 . 9 0}$ & 0.10 \\
\hline Hypothesized Structural Model 2 & 96.787 & $66-29=37$ & 2.616 & $\mathbf{0 . 9 2 9}$ & $\mathbf{0 . 9 5 2}$ & 0.09 \\
\hline Structural model with control variables & 227.097 & $105-35=70$ & 3.2 & $\mathbf{0 . 8 5 3}$ & $\mathbf{0 . 8 8 7}$ & 0.11 \\
\hline
\end{tabular}

16 variables were taken from EFA for analysis in CFA which belonged to the hostility factor, self-control factor and workplace deviance factor. In the first model chi square test was 296.025 with $d f=101, \mathrm{CMIN} / \mathrm{DF}$ was 2.931 (must be $<3$ ), TLI was $\mathbf{0 . 8 7 2}$ (must be $>=0.95$; Schreiber, Stage, King, Nora, Barlow, 2006), CFI was $\mathbf{0 . 8 9 2}$ (must be $>=0.95$; Schreiber, Stage, King, Nora, Barlow, 2006) while RMSEA was 0.1 (must be $<0.06$ to 0.08; Schreiber, Stage, King, Nora, Barlow, 2006). The goodness of fit indices i.e. TLI and CFI not fitted in the first model. All the unstandardized and standardized coefficients were greater than 0.5. After inspection, it was found that even though all the values in the standardized and unstandardized coefficients were significant, but few of the Modification Indices between the error terms were highly correlating with each other and had values more than 10; (i.e.) e38-e39 with MI 17.908 from WDi13 and WDi14, e33-e39 with MI 15.677 from WDo8 and WDi14, e33-e38 with MI 14.489 from WDo8 and WDi13, e33-e34 with MI 13.425 from WDo8 and WDo9, e32-e33 with MI 14.204 from WDo7 and WDo8 and e9-e11 with MI 12.631 from SC17 and SC15. WDi relates to "Workplace Deviance interpersonal" while WDo signifies "Workplace Deviance organizational". All the error terms which belonged to their respective factors were correlated in the model using the correlation symbol in AMOS after which the model was re-run the second time.

In the second model chi square was $213.8, d f=95, \mathrm{CMIN} / \mathrm{DF}$ was 2.25 , TLI was $\mathbf{0 . 9 1 7}$, CFI was $\mathbf{0 . 9 3 4}$ and RMSEA was 0.08. All the values improved; however TLI and CFI were still less than 0.95. Again after examining the unstandardized and standardized coefficients, it was found that SC17 has a factor loading of $\mathbf{0 . 5}$ (which is not $>0.5$ ). SC17 was then removed and the model was re-run the third time. The values of chi square were 186.166, $d f=82$, CMIN/DF was 2.270, TLI was $\mathbf{0 . 9 2 3}$, CFI was $\mathbf{0 . 9 4 0}$ and RMSEA was 0.08. The third model after specification is a better fit than previous models. H3 had a standardized regression coefficient value 
of 0.537 but because it was more than 0.5 therefore the third model is the final hypothesized model which will be taken further for structural analysis (also, mediation) and subsequently the phantom models.

Fig 2: Results of Confirmatory Factor Analysis: Comparative fit index=0.940; Root Mean Square Error of Approximation $=0.08$, chi-square $=186.166 ; \mathrm{df}=82 ; \mathrm{e}=$ error

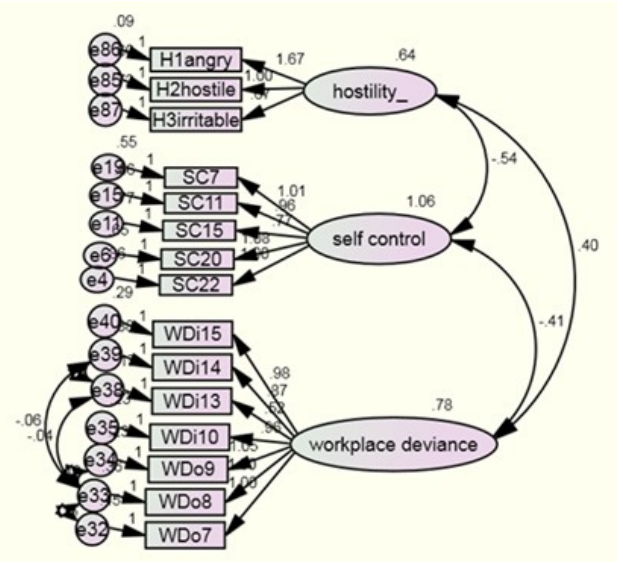

Figure 2 represents the final model created in AMOS 18 after the re-specifications. The figure shows the relationships between observed and latent variables. Three latent variables Hostility, Self-control, and Workplace Deviance have been constructed which are explained by 15 observed variables. SC17 has been removed from the analysis as its standardized coefficient was not greater than 0.5 therefore the e9-e11 correlation was also removed automatically. The figure below shows the standardized estimates in CFA analysis. Also, the five correlations are shown in the figure, from e38-e39, e39-e35, e33-e34, e32-e33, and e35e38.

Table 3: Standardized and Unstandardized Coefficients for CFA

\begin{tabular}{|l|l|l|l|l|}
\hline Observed Variable & Latent Construct & $\boldsymbol{\beta}$ & \multicolumn{1}{l|}{ 促 } & \multicolumn{1}{l|}{ SE } \\
\hline H1angry & Hostility & 0.975 & 1.665 & 0.17 \\
\hline H2hostile & Hostility & 0.718 & 1 & \\
\hline H3irritable & Hostility & 0.537 & 0.674 & 0.099 \\
\hline SC7 & Self-Control & 0.815 & 1.011 & 0.1 \\
\hline SC11 & Self-Control & 0.771 & 0.957 & 0.099 \\
\hline SC15 & Self-Control & 0.671 & 0.773 & 0.094 \\
\hline SC20 & Self-Control & 0.81 & 1.083 & 0.107 \\
\hline SC22 & Self-Control & 0.743 & 1 & \\
\hline WDo7 & Workplace Deviance & 0.796 & 1 & \\
\hline WDo8 & Workplace Deviance & 0.824 & 0.996 & 0.068 \\
\hline WDo9 & Workplace Deviance & 0.888 & 1.053 & 0.081 \\
\hline WDi10 & Workplace Deviance & 0.869 & 0.961 & 0.077 \\
\hline WDi13 & Workplace Deviance & 0.749 & 0.525 & 0.05 \\
\hline WDi14 & Workplace Deviance & 0.78 & 0.874 & 0.08 \\
\hline WDi15 & Workplace Deviance & 0.849 & 0.979 & 0.078 \\
\hline
\end{tabular}

Table 3 represents the standardized coefficients or factor loadings, unstandardized coefficients and the standard errors for each of the observed variables retained in the final hypothesized model having three latent constructs. $\mathrm{H} 2$, SC22, and WDo7 were fixed with the value of "1" as regression weight.

\section{Convergent validities, discriminant validities and construct reliabilities:}

Convergent validities, discriminant validities and construct reliabilities were also calculated and no validity concerns were found. Table 4 shows all the validities and reliabilities for the three latent constructs. All construct reliabilities are greater than 0.7, while AVE is greater than 0.5 and MSV is less than AVE. Also ASV is less than both AVE and MSV. 
Table 4: Convergent validities, discriminant validities and construct reliabilities:

\begin{tabular}{|l|l|l|l|l|l|l|l|}
\hline & CR & AVE & MSV & ASV & self -control & hostility_ & workplace deviance \\
\hline Self- control & 0.875 & 0.583 & 0.428 & 0.316 & 0.764 & - & - \\
\hline hostility_ & 0.800 & 0.585 & 0.428 & 0.371 & -0.654 & 0.765 & - \\
\hline workplace deviance & 0.936 & 0.678 & 0.314 & 0.259 & -0.452 & 0.560 & 0.823 \\
\hline
\end{tabular}

\section{Common Method Variance:}

Method variance occurs due to the measurement method and not due to the construct. Measurement error threatens the validity of the conclusions about the associations between measures. The techniques to control common method biases include Harman's single-factor test and Common latent factor test.

\section{Herman Single Factor test:}

Herman single factor test was run to identify any common method variance. All the 80 variables were entered and only one factor was fixed to identify how much variance is explained by one factor. Only one factor explained $28.052 \%$ of the data, which shows that common method bias is not a major threat in our data set. Table 5 shows that KMO value is greater than 0.5 and significance value of Bartlett's test of sphericity is less than 0.05 . Table 6 shows the variance explained by one factor.

Table 5: KMO and Bartlett's test of sphericity

\begin{tabular}{|l|l|l|}
\hline \multicolumn{2}{|l|}{ KMO and Bartlett's Test ${ }^{\mathbf{a}}$} & .789 \\
\hline Kaiser-Meyer-Olkin Measure of Sampling Adequacy. & 15574.591 \\
\hline Bartlett's Test of Sphericity & Approx. Chi-Square & 3160 \\
\cline { 2 - 3 } & df & .000 \\
\cline { 2 - 3 } & Sig. & \\
\hline
\end{tabular}

Table 6: Total Variance Explained

\begin{tabular}{|l|l|l|l|l|l|l|}
\hline \multirow{2}{*}{ Component } & \multicolumn{4}{|l|}{ Initial Eigenvalues } \\
\cline { 2 - 7 } & Total & \% of Variance & Cumulative \% & Total & \% of Variance & Cumulative \% \\
\hline 1 & 34.895 & 33.431 & 33.431 & 22.441 & 28.052 & 28.052 \\
\hline 2 & 9.513 & 9.114 & 42.545 & & & \\
\hline 3 & 7.066 & 6.769 & 49.314 & & & \\
\hline 4 & 6.105 & 5.849 & 55.163 & & & \\
\hline 5 & 4.895 & 4.689 & 59.852 & & & \\
\hline 6 & 3.404 & 3.261 & 63.113 & & & \\
\hline
\end{tabular}

\section{Common Latent Factor:}

Another test was run to check the common method variance in the data set using common latent factor. Figure 3 shows the common latent factor and its standard coefficients. Table 7 shows that all the delta values were less than 0.2 so common method bias was not a major threat in our data set.

Fig 3: Common Latent Factor Analysis

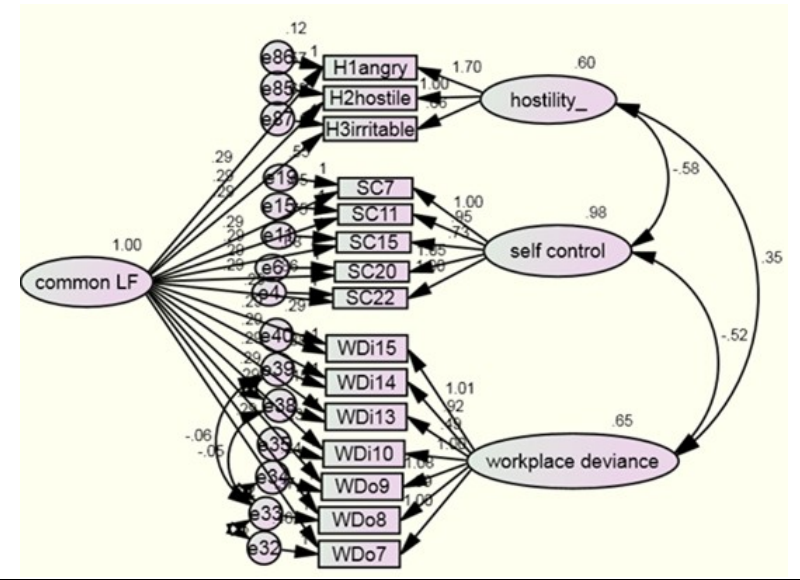


Sleep Deprivation and workplace deviance: a mediation approach

Table 7: Common Latent Factor Test

\begin{tabular}{|c|c|c|c|c|c|}
\hline & & & Estimate (With CLF) & Estimate $\quad$ (No & Delta \\
\hline $\mathrm{SC} 15$ & $<--$ & self -control & 0.62 & 0.671 & 0.051 \\
\hline $\mathrm{SC} 11$ & $<--$ & self -control & 0.739 & 0.771 & 0.032 \\
\hline WDo7 & $<---$ & workplace deviance & 0.738 & 0.796 & 0.058 \\
\hline WDo8 & $<---$ & workplace deviance & 0.764 & 0.824 & 0.06 \\
\hline WDo9 & $<---$ & workplace deviance & 0.838 & 0.888 & 0.05 \\
\hline WDi10 & $<---$ & workplace deviance & 0.821 & 0.869 & 0.048 \\
\hline WDi13 & $<---$ & workplace deviance & 0.634 & 0.749 & 0.115 \\
\hline H2hostile & $\begin{array}{l}<-- \\
\end{array}$ & hostility_ & 0.693 & 0.718 & 0.025 \\
\hline H1 angry & $<---$ & hostility_ & 0.946 & 0.975 & 0.029 \\
\hline WDi15 & $<---$ & workplace deviance & 0.8 & 0.849 & 0.049 \\
\hline WDi14 & $<---$ & workplace deviance & 0.738 & 0.78 & 0.042 \\
\hline $\mathrm{SC} 22$ & $\begin{array}{l}<-- \\
\end{array}$ & self-control & 0.715 & 0.743 & 0.028 \\
\hline $\mathrm{SC} 20$ & $<---$ & self -control & 0.766 & 0.81 & 0.044 \\
\hline SC7 & $<---$ & self-control & 0.78 & 0.815 & 0.035 \\
\hline H3irritable & $<---$ & hostility__ & 0.51 & 0.537 & 0.027 \\
\hline H2hostile & $<---$ & common LF & 0.259 & & \\
\hline H3irritable & $<---$ & common LF & 0.286 & & \\
\hline $\mathrm{SC} 7$ & $<---$ & common LF & 0.228 & & \\
\hline $\mathrm{SC} 11$ & $<---$ & common LF & 0.228 & & \\
\hline $\mathrm{SC} 15$ & $<---$ & common LF & 0.249 & & \\
\hline $\mathrm{SC} 20$ & $<---$ & common LF & 0.214 & & \\
\hline $\mathrm{SC} 22$ & $<---$ & common LF & 0.209 & & \\
\hline WDi15 & $<---$ & common LF & 0.285 & & \\
\hline WDi14 & $<---$ & common LF & 0.288 & & \\
\hline WDi13 & $<---$ & common LF & 0.462 & & \\
\hline WDi10 & $<---$ & common LF & 0.297 & & \\
\hline WDo9 & $<---$ & common LF & 0.279 & & \\
\hline H1 angry & $<---$ & common LF & 0.208 & & \\
\hline WDo7 & $<---$ & common LF & 0.266 & & \\
\hline WDo8 & $<---$ & common LF & 0.279 & & \\
\hline
\end{tabular}

\section{Structural Equation Modeling:}

Figure 4 shows the structural model with chi square 269.047, $d f=$ 95,CMIN/DF 2.832, TLI 0.874, CFI 0.90, and RMSEA 0.1(table 5). The total effect (path c) of sleep deprivation on workplace deviance is $\mathbf{0 . 2 8 7}$, with $p$ value $\mathbf{0 . 0 0 1}$ is significant, direct effect (path c') is $\mathbf{0 . 1 1 8}$ with $p$ value $\mathbf{0 . 2 2 4}$ is non-significance, and indirect path $\left(a^{1} b^{1}\right.$ and $\left.a^{2} b^{2}\right)$ is $\mathbf{0 . 1 7 0}$ with $p$ value $\mathbf{0 . 0 0 6}$ is significant. The total path is significant only because of the indirect path therefore self-control and hostility mediates the relationship between sleep deprivation and workplace deviance. Further analysis was done using phantom models to find which mediator is playing a significant role in between sleep deprivation and workplace deviance.

Fig 4: Structural Equation Model 1. Comparative Fit index $=0.90$; Root Mean Square Error of Approximation $=0.1$; Chi square $=269.047 ; \mathrm{df}=95$. $\mathrm{e}=$ error.

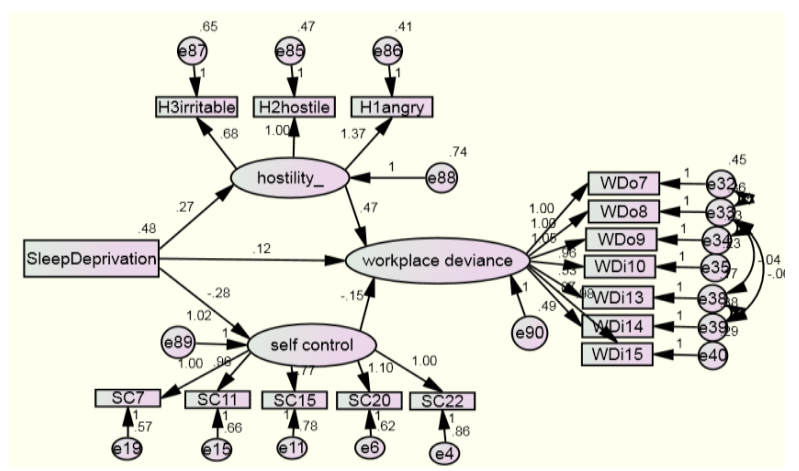


The first phantom model was created in which the indirect effect (path $a^{1} b^{1)}$ was found significant with $\mathbf{0 . 0 0 9} \mathrm{p}$ value and point estimate $\mathbf{0 . 1 2 6}$. The bias corrected lower and upper confidence interval are 0.038and 0.247 which means that there is no zero in between therefore hostility mediates the relationship between sleep deprivation and workplace deviance. The total effect (path c) is $\mathbf{0 . 2 4 3}$, with $\mathbf{0 . 0 0 2} \mathrm{p}$ value $(<0.05$, significant), and direct effect (path c') is $\mathbf{0 . 1 1 8}$ with $\mathrm{p}$ value $\mathbf{0 . 2 2 4}$ ( $>0.05$, non-significant).

The second phantom model showed that the indirect effect (path $\mathrm{a}^{2} \mathrm{~b}^{2)}$ was found non-significant with $\mathbf{0 . 0 5 3} \mathrm{p}$ value and point estimate $\mathbf{0 . 0 4 4}$. The bias corrected lower and upper confidence interval are 0.000 and 0.135 which means that there is a zero therefore self-control does not mediate the relationship between sleep deprivation and workplace deviance. The total effect (path c) is $\mathbf{0 . 1 6 2}$, with $\mathbf{0 . 0 8 5} \mathrm{p}$ value $(>0.05$, nonsignificant), and direct effect (path c') is $\mathbf{0 . 1 1 8}$ with p value $\mathbf{0 . 2 2 4}(>0.05$, non-significant).

Table 8 shows all the standardized and unstandardized regression coefficients for the significant mediating path i.e. hostility between sleep deprivation and workplace deviance. Table 9 shows all the point estimates and bootstrapping results at $95 \%$ Confidence Interval for all the direct, indirect and total paths in structural equation modeling.

Table 8: Results from Structural Equation Modeling

\begin{tabular}{|c|c|c|c|c|c|c|}
\hline \multirow[b]{2}{*}{ Model } & \multicolumn{2}{|l|}{$\boldsymbol{\beta}$} & \multicolumn{4}{|l|}{ B } \\
\hline & Sleep Deprivation & Hostility & Sleep Deprivation & SE & Hostility & SE \\
\hline \multicolumn{7}{|l|}{ Direct } \\
\hline Hostility & 0.211 & & 0.270 & 0.101 & & \\
\hline Workplace Deviance & 0.096 & 0.485 & 0.118 & 0.094 & 0.466 & 0.115 \\
\hline \multicolumn{7}{|l|}{ Indirect } \\
\hline \multicolumn{7}{|l|}{ Hostility } \\
\hline Workplace Deviance & $0.516^{*}$ & & $0.126^{*}$ & 0.051 & & \\
\hline \multicolumn{7}{|l|}{ Total } \\
\hline Hostility & $0.211^{*}$ & & $0.270^{*}$ & 0.101 & & \\
\hline Workplace Deviance & $0.287^{*}$ & $0.485 * *$ & $0.243^{*}$ & 0.085 & $0.466^{* *}$ & 0.115 \\
\hline
\end{tabular}

$\mathrm{N}=165, \mathrm{p}<0.05^{*}, \mathrm{p}<0.01 * *$

Table 9: Point estimates and BC 95\% CI for Indirect effects

\begin{tabular}{|l|l|l|l|}
\hline & & \multicolumn{2}{l|}{ Bootstrapping } \\
\cline { 1 - 1 } & \multirow{3}{*}{ Point Estimate } & Lower & Upper \\
\cline { 1 - 1 } & & & \\
\hline Indirect effects (Hostility) & $0.126^{* *}$ & 0.038 & 0.247 \\
\hline Direct & 0.118 & -0.069 & 0.3 \\
\hline Total & $0.243^{* *}$ & 0.076 & 0.412 \\
\hline & & & \\
\hline Indirect effects (Self-Control) & 0.044 & 0.000 & 0.135 \\
\hline Direct & 0.118 & -0.069 & 0.3 \\
\hline Total & 0.162 & -0.024 & 0.338 \\
\hline
\end{tabular}

$\mathrm{N}=165, \mathrm{p}<0.05^{*}, \mathrm{p}<0.01^{* *}$

\section{Hypothesized Structural Model:}

After finding that self-control had no direct, indirect or total effect on workplace deviance therefore it was removed from the model and the model was tested again with only one mediator i.e. hostility. The chi square was 96.787, $d f=37$, TLI 0.929, CFI 0.952 and RMSEA 0.09 (table 2). The results (table 10) showed that total effect of sleep deprivation on workplace deviance was 0.288 with 0.001 sig level (significant), the direct effect was 0.134 with $0.166 \mathrm{sig}$ level (non-significant) and the indirect effect was 0.155 with 0.011 sig level (significant). 
Table 10: Point estimates and BC 95\% CI for Indirect effects

\begin{tabular}{|l|l|l|l|}
\hline & & \multicolumn{2}{l|}{ Bootstrapping } \\
\hline & \multirow{2}{*}{ Point Estimate } & \multicolumn{2}{l|}{ BC 95\% CI } \\
\cline { 3 - 4 } & & & \multicolumn{2}{l|}{ Upper } \\
\hline Indirect effects (Hostility) & & 0.044 & 0.276 \\
\hline Direct & $0.155^{*}$ & -0.055 & 0.320 \\
\hline Total & 0.134 & 0.125 & 0.453 \\
\hline
\end{tabular}

Fig 5: Hypothesized Structural Equation Model. Comparative Fit index=0.952; Root Mean Square Error of Approximation $=0.09$; Chi square $=96.787 ; \mathrm{df}=37$. $\mathrm{e}=$ error.

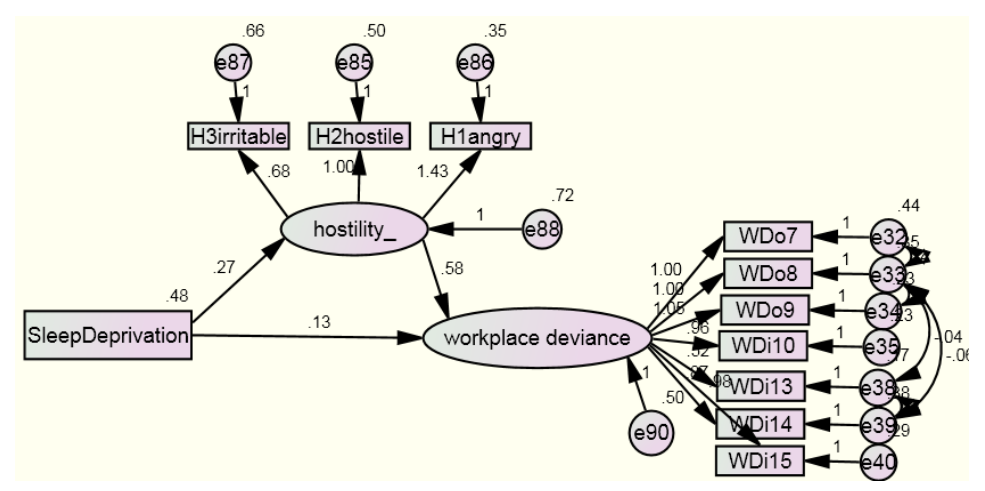

Figure 5 shows the unstandardized regression coefficients for the hypothesized model created. Only hostility has been retained as a significant mediator between sleep deprivation and workplace deviance after confirmatory and structural analysis.

\section{Control Variables:}

Finally, the same structural model was tested using the 7 control variables; chronic insomnia, sleep debt, sleep requirement, hours awake, positive affect, negative affect, and gender. Four variables, gender, negative affect, hours awake, sleep debt were insignificant, therefore they were removed from the model. Chronic insomnia, sleep requirement positive affect were significant in the study. Chi square is 227.097, df 10535=70, CMIN/DF 3.2, TLI 0.853, CFI 0.887 (table 2), chronic insomnia has -0.153regression coefficient with $0.023 \mathrm{p}$ value $(<0.05)$, lower CI-0.289 and upper CI -0.019 , positive effect has -0.301 with $0.000 \mathrm{p}$ value $(<0.05)$, lower CI-0.416 and upper CI -0.179 , sleep requirement is 0.149 with $0.040 \mathrm{sig}$ level $(<0.05)$, lower CI 0.006 and upper CI 0.305 . The total effect of sleep deprivation on workplace deviance is 0.203 with sig level $0.039(<0.05$, significant), lower CI0.015 and upper CI 0.365 , the indirect effect of hostility on workplace deviance is 0.097 with 0.010 sig value $(<0.05$, significant), lower CI 0.025 and upper CI 0.203 , the direct effect of sleep deprivation on workplace deviance is 0.106 with $0.284 \mathrm{p}$ value $(>0.05$, non-significant), lower CI 0.093 and upper CI 0.276 . The total effect is significant due to the indirect effect of hostility. Also the control variables such as chronic insomnia; positive affect and sleep requirement play a major role in affecting workplace deviance.

\section{Discussion}

The above results show that sleep deprivation does not have a direct impact on workplace deviance. The total effect of sleep deprivation on workplace deviance is significant only because it is mediated through hostility. Also, self- control does not mediate the relationship between sleep deprivation and workplace deviance. The structural model is a good fit when self-control was removed from the model. All the reliabilities and validities are good and not a concern in the study. Common method variance is also not a major threat in this research. Hypothesis 1 is accepted as the total effect was significant in the study. Self-control does not mediate the relationship between sleep deprivation and workplace deviance therefore Hypothesis 2 is rejected. State hostility fully mediates the relationship between sleep deprivation and workplace deviance therefore Hypothesis 3 is also rejected. These results are different from that of Christian and Ellis [68], in which they have used Baron and Kenny approach to mediation, and Preacher and Hayes approach to bootstrapping multimediators. The hypothesis in their study has been accepted in which both self-control and hostility partially mediates the relationship between sleep deprivation and workplace deviance. Comparatively, in this research 
self-control has no significance between sleep deprivation and workplace deviance but state hostility fully mediates their relation.

\section{Theoretical Implications}

The findings suggest that the impact of sleep deprivation has implications in various organizational fields. Sleep loss reduces employee's ability to regulate emotions effectively, therefore these results are critical for occupations in which display of emotions are important such as, customer services, in which service officers are frequently required to control their emotions. These officers may become angry and annoyed and may be unable to hide their negative feelings when they deal with enraged customers if they are sleep deprived. The results suggest that sleep deprived employees are unable to confine their impulses to involve in risky behaviors such as abuse, injuries, accidents, criminal actions and lack of good inter personal relationships. The sleep deprived individuals indulge in malevolence and socially deviant acts which are associated with unethical behavior. Besides, for medical residents, it is very important to regulate their emotions effectively and endure patience and perseverance during their house job as they deal with different types of patients along with learning and studies.

\section{Managerial Implications}

Sleep deprivation can be reduced if managers use tactics such as sleep awareness training programs (insomnia reduction plans). It can also be reduced if managers redesign jobs which will reduce long working hours and stressful working conditions (such as, scheduling and restricting overtime). Companies can implement policies that can help employees sleep additionally through "workplace napping". The role of corporate culture is also very important in creating conditions that leads to sleep deprivation therefore managers must be aware about these conditions as well. Workplace deviance will be highly observed in organizations that encourage workaholic cultures where employees are expected to work extended hours. Organizational injustice may also lead to insomnia thus managers must also be attentive and responsive of the workplace justice. Employees with parental responsibilities are also sleep deprived therefore managers should create flexible sleep-friendly environment by implementing family-friendly policies like parental leave. In some professions, sleep deprivation is inevitable, like, military personnel, and health care professionals. Managers must be aware about their emotions and stay alert of potentially high-risk employees by monitoring their current levels of functioning in order to reduce any potential negative events to occur at work. Managers can take restorative approaches like giving frequent breaks or providing caffeine which will increase their tolerance to the effects of sleep loss.

\section{Conclusion}

The effects of sleep deprivation have been ignored in the past even though sleep deprivation has increased in the workplace. This study has focused on one of the most important antecedents of workplace deviance, namely, sleep deprivation. The evidence for sleep deprivation as a significant cause has been drawn from social and organizational psychology along with neuroscience has highlighted the causes of workplace deviance in this study. If the research efforts continue, sleep research will become more important in understanding the behavior of employees in organizations. There were few limitations related to time and access to respondents, also the sample size was 165 which is very small. Besides that, this study could further have been taken in other professions such as Pakistan military or army or multinational executives to give more insight into the effects of sleep deprivation on deviant behaviors. For future researchers, the antecedents of sleep deprivation can also be studied to give more insight into the black box to find more profound reasons for workplace deviance and its occurrence.

\section{REFERENCES}

[1] Bennett, R. J., \& Robinson, S. L. 2000.Development of a measure of workplace deviance. Journal of Applied Psychology, 85: 349360 .

[2] Harper, D. 1990.Spolight abuse-save profits. Industrial distribution, 79: 47-51.

[3] DePaulo, P.J., \& DePaulo, B.M. 1989. Can deception by salespeople and customers be detected through nonverbal behavioural cues?, Journal of Applied Social Psychology, 19: 1552-1577.

[4] Kidwell, R. E., \& Bennett, N. 1993. Employee propensity to withhold effort: A conceptual model to intersect three avenues of research. Academy of Management Review, 18: 429-456.

[5] Fox, S., \& Spector, P.E. 1999.A model of work frustration-aggression. Journal of Organisational Behaviour, 20: 915-913.

[6] Johns, G. 1997. "Contemporary research on absence from work: correlates, causes, and consequences", In Cooper, C.L. and Robertson, I.T. (Eds.), International Review of Industrial and Organisational Psychology, 12,John Wiley \& Sons, London, 115-174.

[7] Fisher, C.D. 2003. Why do lay people believe that satisfaction and performance are correlated? Possible sources of a common sense theory. Journal of Organisational Behaviour, 24: 753-777.

[8] Griffin, R.W., \& Y. P. Lopez. 2005. "Bad behaviour" in organizations: a review and typology for future research. Journal of Management, 31: 988.

[9] Fisher, C.D. 2002. Antecedents and consequences of real-time affective reactions at work. Motivation \& Emotion, 26: 3-30.

[10] Peterson. 2002. Deviant workplace behaviour and the organisation's ethical climate. Journal of Business and Psychology, 17: 4756. 
[11] Galperin, B., \& Burke, R.J. 2006. Uncovering the Relationship between Workaholism and Workplace Destructive and Constructive Deviance: An Exploratory Study. International Journal of Human Resource Management, 17:331-347.

[12] Akinbode, G.A. 2009. Effects of gender and organisational factors on workplace deviant and fraudulent behaviours. Journal of Management and Entrepreneur, 2:53-79.

[13] Robinson, S. L., \& Bennett, R. J. 1995. A typology of deviant workplace behaviour's: A multidimensional scaling study. Academy of Management Journal, 38: 555-572.

[14] Omar, Halim, Zainah, Farhadi, Nasir \& Kairudin. 2011. Stress and job satisfaction as antecedents of workplace deviant behaviour. World Applied Sciences Journal, 12:45-51.

[15] Giacalone, R., Riordan, C.,\& Rosenfeld, P. 1997. Employee sabotage: Toward a practitioner-scholar understanding. In R. Giacalone \& J. Greenberg (Eds.), Antisocial behaviour in organizations: 109-129. Thousand Oaks, CA: Sage.

[16] Baumeister, R., Heatherton, T., \& Tice, D. 1994.Losing control: How and why people fail at self-regulation. San Diego: Academic.

[17] Schmeichel, B., \& Baumeister, R. 2004. Self-regulatory strength. In R. Baumeister \& K. Vohs (Eds.), Hand book of selfregulation: Research, theory, and applications:84-98. New York: Guilford. Scott, B., \& Judge, T. 2006. Insomnia, emotions, and job satisfaction: A multilevel study. Journal of Management, 32: 622-645.

[18] Thomas, M., Sing, H., Belenky, G., Holcomb, H., Mayberg, H., Dannals, R., Wagner, H., Thorne, D., Popp, K., \& Rowland, L. 2000. Neural basis of alertness and cognitive performance impairments during sleepiness: Effects of $24 \mathrm{~h}$ of sleep deprivation on waking human regional brain activity. Journal of Sleep Research, 9: 335-352.

[19] Harrison, Y., \& Horne, J. A. 2000. The impact of sleep deprivation on decision making: A review. Journal of Experimental Psychology: Applied, 6: 236-249.

[20] Barnes, C. M., \& Wagner, D. T. 2009. Changing to daylight saving time cuts into sleep and increases workplace injuries. Journal of Applied Psychology, 94: 1305- 1317.

[21] Muraven, M., \& Baumeister, R. F. 2000. Self-regulation and depletion of limited resources: Does self-control resemble a muscle? Psychological Bulletin, 126: 247-259.

[22] Twenge, J., Muraven, M., \& Tice, D. 2004. Measuring state self-control: Reliability, validity, and correlations with physical and psychological stress. Unpublished manuscript, San Diego State University.

[23] Watson, D., \& Clark, L. 1994. The PANAS-X: Manual for the positive and negative affect schedule-expanded form. Unpublished manuscript, University of Iowa.

[24] Martinko, M., Gundlach, M., \& Douglas, S. 2002. Toward an integrative theoryof counterproductive workplace behaviour: A causal reasoning perspective. International Journal of Selection and Assessment, 10: 36-50.

[25] Spector, P., \& Fox, S. 2005. The stressor-emotion model of counterproductive work behaviour. In S. Fox \& P. Spector (Eds.), Counterproductive work behaviour: Investigations of actors and targets: 151-174. Washington, DC: American Psychological Association.

[26] Bordia, P., Restubog, S. L. D., \& Tang, R. L. 2008. When employees strike back: Investigating Mediating mechanisms between psychological contract breach and workplace deviance. Journal of Applied Psychology, 93: 1104-1117.

[27] Lee, K., \& Allen, N. J. 2002. Organizational citizenship behaviour and workplace deviance: The role of affect and cognitions. Journal of Applied Psychology, 87: 131-142.

[28] Baumeister, R. F., Gailliot, M., DeWall, C. N., \& Oaten, M. 2006. Self-regulation and Personality: How interventions increase regulatory success, and how depletion moderates the effects of traits on behaviour. Journal of Personality, 74: 1773-1801.

[29] Baumeister, R., \& Vohs, K. 2007. Self-regulation, ego depletion, and motivation. Social and Personality Psychology Compass, 1: $115-128$.

[30] Baumeister, R., \& Vohs, K. 2003. Self-regulation and the executive function of the self. In M. Leary \& J. Tangney (Eds.), Handbook of self and identity: 197-217. New York: Guilford.

[31] DeWall, C., Baumeister, R., Stillman, T., \& Gailliot, M. 2007. Violence restrained: Effects of self-regulatory capacity and its depletion on aggressive behaviour. Journal of Experimental Social Psychology, 43: 62- 76.

[32] Gailliot, M. T., Schmeichel, B. J., \& Baumeister, R. F. 2006. Self-regulatory processes defend against the threat of death: Effects of self-control depletion and trait self-control on thoughts and fears of dying. Journal of Personality and Social Psychology, 91: 4962.

[33] Tangney, J. P., Baumeister, R. F., \& Boone, A. L. 2004.High self-control predicts good adjustment, less pathology, better grades, and interpersonal success. Journal of Personality, 72: 271-324.

[34] Mead, N. L., Baumeister, R. F., Gino, F., Schweitzer, M. E., \& Ariely, D. 2009. Too tired to tell the truth: Self-control, resource depletion, and dishonesty. Journal of Experimental Social Psychology, 45: 594-597.

[35] Marcus, B., \& Schuler, H. 2004. Antecedents of counterproductive behaviour at work: A general perspective. Journal of Applied Psychology, 89: 647-660.

[36] Douglas, S. C., \& Martinko, M. J. 2001. Exploring the role of individual differences in the prediction of workplace aggression. Journal of Applied Psychology, 86: 547-559.

[37] Davidson, R. J., Putnam, K. M., \& Larson, C. L. 2000.Dysfunction in the neural circuitry of emotion regulation-A possible prelude to violence. Science, 289: 591-594.

[38] Urry, H. L., van Reekum, C. M., Johnstone, T., Kalin, N. H., Thurow, M. E., Schaefer, H. S., Jackson, C. A., Frye, C. J., Gre ischar, L. L., \& Alexander, A. L. 2006. Amygdala and ventromedial prefrontal cortex are inversely coupled during regulation of negative affect and predict the diurnal pattern of cortisol secretion among older adults. Journal of Neuroscience, 26: 4415-4425.

[39] Finkel, E. J., \& Campbell, W. K. 2001. Self-control and accommodation in close relationships: An interdependence analysis. Journal of Personality and Social Psychology, 81: 263-277.

[40] Durmer, J. S., \& Dinges, D. F. 2005. Neurocognitive consequences of sleep deprivation. Seminars in Neurology, 25: 117-129.

[41] Pilcher, J. J., Ginter, D. R., \& Sadowsky, B. 1997. Sleep quality versus sleep quantity: Relationships between sleep and measures of health, well-being and sleepiness in college students. Journal of Psychosomatic Research, 42: 583-596.

[42] Zohar, D., Tzischinsky, O., Epstein, R., \& Lavie, P. 2005. The effects of sleep loss on medical residents' emotional reactions to work events: A cognitive-energy model. Sleep, 28: 47-54.

[43] Judge, T. A., Scott, B. A., \& Ilies, R. 2006. Hostility, job attitudes, and workplace deviance: Test of a multilevel model. Journal of Applied Psychology, 91: 126-138.

[44] Fox, S., Spector, P.E., \& Miles, D. 2001. Counterproductive work behaviour (CWB) in response to job stress ors and organisational justice: Some mediator and moderator tests for autonomy and emotions. Journal of Vocational Behaviour, 59: 291-309.

[45] Spector, P., \& Fox, S. 2002. An emotion-centered model of voluntary work behaviour: Some parallels between counterproductive work behaviour and organizational citizenship behaviour. Human Resource Management Review, 12: $269-292$. 
[46] Harmon-Jones, E., \& Sigelman, J. 2001. State anger and prefrontal brain activity: Evidence that insult-related relative leftprefrontal activation is associated with experienced anger and aggression. Journal of Personality and Social Psychology, 80: 797803 .

[47] Tice, D., \& Bratslavsky, E. 2000. Giving in to feel good: The place of emotion regulation in the context of general self-control. Psychological Inquiry, 11: 149-159.

[48] Tice, D. M., Bratslavsky, E., \& Baumeister, R. F. 2001.Emotional distress regulation takes precedence over impulse control: If you feel bad, do it! Journal of Personality and Social Psychology, 80: 53-67.

[50] Beal, D. J., Weiss, H. M., Barros, E., \& MacDermid, S. M. 2005. An episodic process model of affective influences on performance. Journal of Applied Psychology, 90: 1054-1068.

[51] Zillmann, D. 1993. Mental control of angry aggression. In D. Wegner \& J. Pennebaker (Eds.), Handbook of mental control, vol. 5: 370-392. Englewood Cliffs, NJ: Prentice Hall.

[52] Weinger, M., \& Ancoli-Israel, S. 2002. Sleep deprivation and clinical performance. Journal of the American Medical Association, 287: 955-957.

[53] Saper, C. B., Scammell, T. E., \& Lu, J. 2005. Hypothalamic regulation of sleep and circadian rhythms. Nature, 437: $1257-1263$.

[54] Barnes, C., \& Hollenbeck, J. 2009. Sleep deprivation and decision-making teams: Burning the midnight oil or playing with fire? Academy of Management Review, 34: 56-66.

[55] Ferrara, M., \& De Gennaro, L. 2001. How much sleep do we need? Sleep Medicine Reviews, 5: 155-179.

[56] Van Dongen, H. P., Baynard, M. D., Maislin, G., \& Dinges, D. F. 2004. Systematic interindividual differences in neurobehavioral impairment from sleep loss: Evidence of trait-like differential vulnerability. Sleep, 27: 423-433.

[57] Blagrove, M., Alexander, C., \& Horne, J. 1995. The effects of chronic sleep reduction on the performance of cognitive tasks sensitive to sleep deprivation. Applied Cognitive Psychology, 9: 21-40.

[58] McKenna, B. S., Dickinson, D. L., Orff, H. J., \& Drummond, S. P. 2007. The effects of one night of sleep deprivation on knownrisk and ambiguous-risk decisions. Journal of Sleep Research, 16: 245-252.

[59] Damasio, A. 1994.Descartes' error: Emotion, rationality and the human brain. New York: Putnam.

[60] Miller, E. K. 2000. The prefrontal cortex and cognitive control. Nature Reviews. Neuroscience, 1: 59-65.

[61] Jennings, J., Monk, T., \& Van der Molen, M. 2003. Sleep deprivation influences some but not all processes of supervisory attention. Psychology Science, 14: 473-479.

[62] Reynolds, B., \& Schiffbauer, R. 2004. Measuring state changes in human delay discounting: An experiential discounting task. Behavioural Processes, 67: 343-356.

[63] Anderson, S. W., Bechara, A., Damasio, H., Tranel, D., \&Damasio, A. R. 1999. Impairment of social and moral behaviour related to early damage in human prefrontal cortex. Nature Neuroscience, 2: 1032-1037.

[64] Masicampo, E., \& Baumeister, R. 2008. Toward a physiology of dual-process reasoning and judgment: Lemonade, willpower, and expensive rule-based analysis. Psychology Science, 19: 255-260.

[65] Dahl, R. E., \& Lewin, D. S. 2002. Pathways to adolescent health sleep regulation and behaviour. Journal of Adolescent Health, 31: $175-184$.

[66] Pilcher, J. J., \& Huffcutt, A. I. 1996. Effects of sleep deprivation on performance: A meta-analysis. Sleep, 19: $318-326$.

[67] Podsakoff, P. M., MacKenzie, S. B., Lee, J. Y., \& Podsakoff, N. P. (2003). Common method biases in behavioral research: a critical review of the literature and recommended remedies. Journal of applied psychology, 88(5), 879.

[68] Christian, M. S., \& Ellis, A. P. 2011. Examining the effects of sleep deprivation on workplace deviance: A self-regulatory perspective. Academy of Management Journal, 54:913-934.

[69] Okun, M.L., Kravitz, H.M., Sowers, M.F., Moul, D.E., Buysse, D.J., \& Hall, M. (2009). Psychometric evaluation of the Insomnia Symptom Questionnaire: A self-report measure to identify chronic insomnia. Journal of Clinical Sleep Medicine, 5(1), $41-51$. 